\title{
RESEARCH
}

Open Access

\section{Neonatal ten-year retrospective study on neural tube defects in a second level University Hospital}

\author{
Ettore Piro $^{*}$ D, Gregorio Serra, Ingrid Anne Mandy Schierz, Mario Giuffrè and Giovanni Corsello
}

\begin{abstract}
Background: Aim of this retrospective study was to describe clinical characteristics, diagnostic work-up, management and follow-up of newborns with neural tube defects (NTDs), admitted to the Mother and Child Department of the University Hospital of Palermo, in a ten years period.

Methods: The medical records of 7 newborns ( 5 males and 2 females) admitted, over a 10-year period from January 2010 to March 2020, to our Department on the first day of life were reviewed. Analyzed data were related to familiar and/or maternal risk factors (consanguinity, maternal preexisting and/or gestational diseases, exposure to teratogen/infectious agents, lack of preconception folic acid supplement), demographic (ethnicity/origin, residence) and clinical features (eventual use of assisted reproduction techniques, prenatal diagnosis, gestational age, fetal presentation, type of delivery, birth weight, preoperative imaging, antibiotics and analgesics use, description of the surgery intervention, length of hospital stay, comorbidities, complications), and follow-up.

Results: In our sample we observed a wide spectrum of NTDs: 3 newborns had open NTDs, namely myelomeningocele (2 lumbosacral, one of which associated with extradural lipoma, and 1 sacral), and 4 closed ones, including 2 with meningocele (occipital), 1 filar lipoma associated with dermal sinus, and 1 terminal myelocystocele. Our patients were discharged between 8 and 22 days of life.

The neurodevelopmental follow-up showed a favorable outcome for 4 of the 7 patients, and the appearance over time of neurological impairment (motor and/or autonomic) in the newborns with open NTDs.

Conclusions: This study describes familiar and/or maternal risk factors and demographic and clinical features of a single-center series of newborns with NTDs. It may provide a further outline of the actual phenotypic spectrum of these malformations, and new insights into epidemiological aspects and comprehensive management of the patients, including diagnostic work-up and follow-up evaluations.
\end{abstract}

Keywords: NTDs, Spina bifida, Newborn, Clinical management, Neurodevelopmental follow-up, Prevention

\footnotetext{
*Correspondence: ettore.piro@unipa.it

Department of Health Promotion Sciences, Maternal and Infant Care, Internal Medicine and Medical Specialties "G. D'Alessandro", University of Palermo, Piazza delle Cliniche, 2, 90127 Palermo, Italy
}

(c) The Author(s). 2020 Open Access This article is licensed under a Creative Commons Attribution 4.0 International License, which permits use, sharing, adaptation, distribution and reproduction in any medium or format, as long as you give appropriate credit to the original author(s) and the source, provide a link to the Creative Commons licence, and indicate if changes were made. The images or other third party material in this article are included in the article's Creative Commons licence, unless indicated otherwise in a credit line to the material. If material is not included in the article's Creative Commons licence and your intended use is not permitted by statutory regulation or exceeds the permitted use, you will need to obtain permission directly from the copyright holder. To view a copy of this licence, visit http://creativecommons.org/licenses/by/4.0/ The Creative Commons Public Domain Dedication waiver (http://creativecommons.org/publicdomain/zero/1.0/) applies to the data made available in this article, unless otherwise stated in a credit line to the data. 


\section{Background}

Neural tube defects (NTDs) are congenital malformations of the central nervous system [1]. They are caused by partial/incomplete closure of the neural tube during embryogenesis, between 21 and 28 days after conception $[2,3]$. Disorders of primary neurulation include craniorachischisis in which the neural tube fails to initiate closure, leaving most of the brain and the entire spine open. If closure initiates successfully, then the cranial and/or spinal neural folds may fail to close generating exencephaly/anencephaly and open spina bifida (myelomeningocele). Malformations resulting from disturbance of secondary neurulation are closed (skin covered) and often involve tethering of the spinal cord, with associated ectopic lipomatous material $[4,5]$. Nevertheless, recent evidences support a post-neurulation origin for encephalocele and demonstrate that brain herniation and failure of brain/spine neural tube closure can all occur as possible developmental outcomes of an identical genetic defect [6]. Infants with anencephaly are mostly stillborn, or die shortly after birth, while those with spina bifida and encephalocele may survive, although suffering from physical and developmental disabilities of various degrees of severity [7]. Worldwide average incidence is $1.8 / 1000$ births (more than 300,000 affected infants born every year), with significant geographic (ethnic, environmental, socioeconomic) variations ( $>1$ to around 10/1000 births in middle and lowincome countries (LMICs) and decreasing incidence in high-income countries (HICs, $0.6 / 1000$ in USA) in the recent decades $[8,9]$.

NTDs are among the main causes of childhood mortality and disability worldwide, with higher rates in LMICs for limited access to specialized neonatological/ pediatric and surgical care [8-10]. Moreover, inequities in the access to high quality care affect pregnant/childbearing age women [11], in relation to low rate of prenatal diagnosis and prevention tools (preconception folic acid supplement), thus explaining the higher prevalence of NTDs at birth.

Here we report on a ten years retrospective study of newborns with NTDs assisted at the Mother and Child Department of the University Hospital of Palermo (Sicily, Italy). The aim of the study was to describe epidemiological aspects and clinical characteristics of these patients, as well as diagnostic work-up, comprehensive management and updated follow-up. To the best of our knowledge, our report is the first in Western Sicily concerning these malformations.

\section{Methods}

\section{Patients}

This is a retrospective study, conducted over a 10-year period from January 2010 to March 2020, on all newborns with neural tube defects (NTDs) admitted to the Mother and Child Department of the University Hospital of Palermo (Sicily, Italy). Our Department includes 3 Operative Units: Obstetrics and Gynecology, Neonatology and Neonatal Intensive Care and Pediatric Surgery. The latter is one of the few in Sicily (which is among the most populated Italian regions, with around 5 million inhabitants and 40,000 newborns estimated in 2019) to take care of these malformations. In the decade under investigation, the catchment population of our Department (spanning almost all Western Sicily, i.e. the provinces of Agrigento and Caltanissetta besides that of Palermo) was of about 175.000 newborns.

Data collected by neonatal records and follow-up charts were related to familiar and/or maternal risk factors (consanguinity, maternal preexisting and/or gestational diseases, exposure to teratogen/infectious agents, lack of preconception folic acid supplement), demographic (ethnicity/origin, residence), clinical features (eventual use of assisted reproduction techniques, prenatal diagnosis, gestational age, fetal presentation, type of delivery, birth weight, preoperative imaging, modalities of pharmacological prophylaxis and/or therapy with antibiotics and analgesics, description of the surgery intervention, length of hospital stay, comorbidities, complications), and neurodevelopmental outcomes. Ethical approval was granted from the Ethics Committee of our University Hospital.

\section{Results}

Seven patients were included in this study ( 5 males and 2 females). All of them were admitted on the first day of life, 4 inborn, and 3 were transferred from other first level birth centers.Ethnicity was Sicilian for all newborns except for one, whose parents were from Ghana.

No consanguinity was found in any case. Five families lived in the urban area and two came from a rural area. All patients were naturally conceived. Two women with preexisting diseases were observed, one with severe obesity, and the other with HIV infection. No mother received preconception folic acid supplement, and only one woman took folate during pregnancy. A prenatal diagnosis was performed in only 2 (1 lumbosacral myelomeningocele, and 1 terminal myelocystocele) of 7 subjects. All newborns, except one (35 WG), were at term. All had cephalic presentation. Four were born by vaginal delivery (one of which was precipitous), and 3 by caesarean section. Two were low-birth-weight infants $(<2500 \mathrm{~g})$. The length of hospitalization ranged from 8 to 22 days.

\section{Clinical features}

A wide spectrum of NTDs was observed in our patients: three had open NTDs, namely myelomeningocele 
(MMC, 2 lumbosacral, one of which associated with extradural lipoma and concomitant split cord malformation, and 1 sacral), and 4 closed ones, including 2 with occipital meningocele, 1 filar lipoma associated with dermal sinus, and 1 terminal myelocystocele. Three patients had associated anomalies and/or comorbidities: 1 cerebellar and corpus callosum hypoplasia and feet deformities, with normal array comparative genomic hybridization (a-CGH) findings, 1 hypospadias, and 1 HIV infection, severe perinatal asphyxia, and congenital microcephaly (head circumference below 2 SD). Images related to the newborn with MMC and split cord malformation are showed in Fig. 1.

\section{Medical imaging}

All patients performed in the first days of life ultrasound (US) examinations of brain, skin and soft tissues over the spine, abdomen and heart. The newborn affected by filar lipoma performed also lumbosacral X-ray. In the two patients with occipital meningocele, Computed Tomography (CT) of the head in one case, and brain and spine Magnetic Resonance Imaging (MRI) in the other one, were performed to rule out a cerebral parenchymal involvement. Ophthalmological evaluation was performed in both of them. In the 2 newborns with $M M C$, cerebral US showed triventricular hydrocephalus along with cerebellar and corpus callosum hypoplasia in one subject, and isolated non progressive enlargement of the lateral ventricles in the other one. In the patient with myelocystocele an isolated cavitation of choroid plexus was observed.

\section{Treatment and neurodevelopmental outcomes}

A surgical procedure was performed in 5 of the 7 patients in neonatal age within $72 \mathrm{~h}$ of life, 3 with open NTDs and two with occipital meningocele. In three newborns with MMC, it consisted of a direct approach, preserving maximum healthy skin to allow a closure of the defect. An incision between the dura mater and the skin around the neural placode was performed. A progressive dissection and identification of the meningeal plan, until the basis of the bone cleft, was made. An opening of the dural sac was carried out, then the dura was sutured with very fine polydioxanone continuous suture before skin closure. One of these three patients underwent a contextual excision of a lipomatous extradural lesion in the upper third of the defect, another one a simultaneous ventriculoperitoneal shunting for concomitant hydrocephalus, and the third an additional lateral relaxing incisions in the fascia for primary skin defect closure. In the newborns with occipital meningocele, the intervention consisted of a simple section of the defect on its basis, with covering of the bone abnormality with surrounding tissue, and then closure of the scalp. All patients underwent parenteral antibiotic prophylaxis and analgesic therapy during surgical procedures and, except for the preterm one, who was further supported by mechanical ventilation, they were spontaneously breathing at the end of operating session.

The postoperative evolution was uneventful in all cases, with the exception of a newborn with MMC suffering from a surgical wound dehiscence, that healed in 10 days. No deaths occurred in the present case series. At follow-up, the two patients with MMC presented with the expected severe neurological impairment related to the spinal segment involvement above L3. A female patient aged 5 years, with concomitant cerebral anomalies, is also affected by a global developmental delay. The youngest patient with MMC, aged two months, has a reduced motility of lower limbs and fecal incontinence and no cerebral ventricular dilatation. The preterm patient with lumbosacral spina bifida, aged 5 years, achieved autonomic walking at two years of age, normal urinary and fecal continence, and shows a normal cognitive developmental level. The third newborn with MMC and associated extradural lipoma, does not have a significant follow-up time (as she currently is 3 months old), and actually shows hypoesthesia and

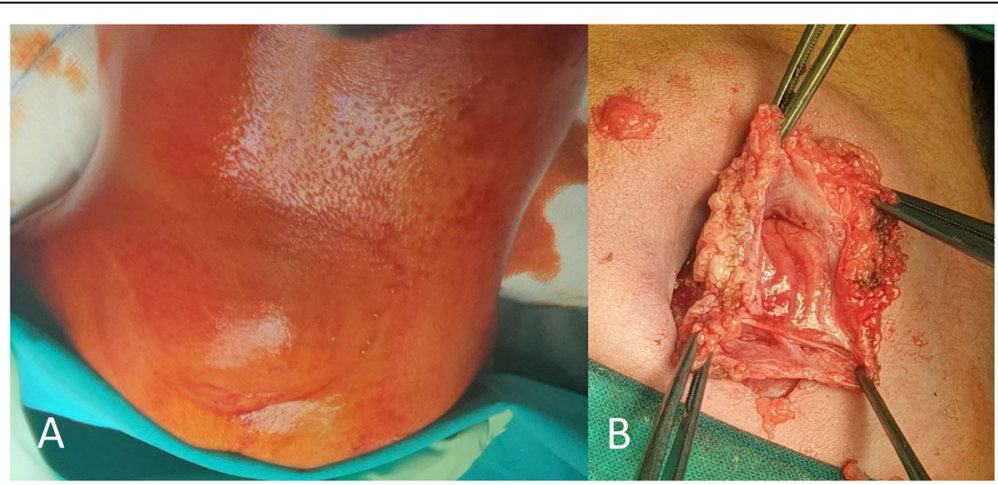

Fig. 1 Female neonate with lumbosacral lipomyelomeningocele (a); an associated split cord malformation was evident during surgery (b) 
reduced motility of the lower limbs. The male patient with isolated occipital meningocele underwent surgical correction at three months of age, and now, aged 7 years, has a normal neurodevelopmental profile. The male infant with filar lipoma and dermal sinus at three months of age shows a normal lower limbs motility and fecal continence. He has not yet been operated, in relation to the parental will to wait for a greater age. The patient with terminal myelocystocele was operated at three months of age, and now, aged 10 years, he has a normal global neurodevelopmental profile. Epidemiological and clinical data are summarized in Tables 1 and 2.

\section{Discussion}

The term "spina bifida" was first coined in 1641 by Nicholas Tulp [12]. The spread of surgical treatment of open NTDs and the knowledge of pathophysiology (including primary prevention through folic acid preconception supplement), epidemiology and genetics of such defects were reached much later, in the late twentieth century [9].

Most NTDs are sporadic and multifactorial: an oligogenic/polygenic inheritance (genes regulating folate and methionine metabolism, and others involved in planar cell polarity signaling pathway) interact with influencing environmental factors $[4,5,13]$. Risk factors include: maternal folate deficiency, diabetes, obesity, exposure to teratogens (valproic acid and carbamazepine, lead and tetrachloroethylene-contaminated drinking water, arsenic, pesticides, mycotoxins, fungus contaminants of maize, heat, influenza virus), specific parental occupations and low socioeconomic status $[4,14]$. Recurrence risk of a second affected child is increased by 3-5 folds for couples with one sick infant, compared to the general population. A significant proportion (10\%) of NTDs are associated with syndromes and/or chromosomal anomalies/congenital malformations, and the correlation is more marked $(20 \%)$ in some ethnic groups (i.e. Arab populations with increased prevalence of autosomal recessive diseases, reflecting their high coefficient of

Table 1 Epidemiological data of present patients

\begin{tabular}{ll}
\hline SEX & $\cdot 5$ males \\
TYPE OF ADMISSION & $\cdot 2$ females \\
& $\cdot 4$ inborn \\
ORIGIN (ethnicity) & $\cdot 3$ outborn \\
& $\cdot 6$ Sicilian (European) \\
RESIDENCE & $\cdot 1$ Ghanaian (African) \\
PREEXISTING MATERNAL DISEASES & $\cdot 5$ urban area \\
FOLIC ACID SUPPLEMENT & $\cdot 2$ rural area \\
& $\cdot 1$ severe obesity \\
& $\cdot 1$ HIV infection \\
& $\cdot 0$ preconception \\
\end{tabular}

Table 2 Clinical characteristics of present patients

\begin{tabular}{|c|c|}
\hline PRENATAL DIAGNOSIS & $\begin{array}{l}\text { 2/7 newborns } \\
\cdot 1 \text { lumbosacral myelomeningocele } \\
\cdot 1 \text { terminal myelocystocele }\end{array}$ \\
\hline GESTATIONAL AGE & $\begin{array}{l}\text { - } 6 \text { at term } \\
\text {. } 1 \text { preterm ( } 35 \text { WG) }\end{array}$ \\
\hline TYPE OF DELIVERY & $\begin{array}{l}\text { - } 4 \text { vaginal ( } 1 \text { precipitous) } \\
\text {. } 3 \text { cesarean section }\end{array}$ \\
\hline TYPE OF NEURAL TUBE DEFECT & $\begin{array}{l}\text { - } 3 \text { open: MMC, } 2 \text { lumbosacral, one } \\
\text { of which associated with extradural } \\
\text { lipoma, and } 1 \text { sacral } \\
\text { - } 4 \text { closed: } 2 \text { occipital meningocele, } \\
1 \text { filar lipoma associated with dermal } \\
\text { sinus, } 1 \text { terminal myelocystocele }\end{array}$ \\
\hline $\begin{array}{l}\text { ASSOCIATED ANOMALIES AND/ } \\
\text { OR COMORBIDITIES }\end{array}$ & $\begin{array}{l}\text { 3/7 newborns } \\
\cdot 1 \text { cerebellar and corpus callosum } \\
\text { hypoplasia and feet deformities, } \\
\text { with normal a-CGH findings } \\
\cdot 1 \text { hypospadias } \\
\cdot 1 \text { HIV infection, severe perinatal } \\
\text { asphyxia, and congenital } \\
\text { microcephaly }(<-2 S D)\end{array}$ \\
\hline $\begin{array}{l}\text { MEDICAL IMAGING/SPECIALISTIC } \\
\text { EVALUATIONS }\end{array}$ & $\begin{array}{l}\cdot \text { 7/7 US of brain, skin and soft tissues } \\
\text { over the spine, abdomen and heart } \\
\cdot 1 / 7 \text { lumbosacral X-ray } \\
\cdot 1 / 7 C T \text { of the head } \\
\cdot \text { 1/7 brain and spine MRI } \\
\cdot \text { 2/7 ophthalmological evaluation }\end{array}$ \\
\hline SURGICAL PROCEDURE & $\begin{array}{l}5 / 7 \text { newborns } \\
\cdot 3 \mathrm{MMC} \\
\cdot 2 \text { meningocele }\end{array}$ \\
\hline POSTOPERATIVE EVOLUTION & $\begin{array}{l}\text { - 4/5 uneventful } \\
\cdot 1 / 5 \text { surgical wound dehiscence }\end{array}$ \\
\hline $\begin{array}{l}\text { NEURODEVELOPMENTAL } \\
\text { OUTCOMES }\end{array}$ & $\begin{array}{l}\text { - } 3 \text { normal neurodevelopmental } \\
\text { profile and/or normal lower limbs } \\
\text { motility and fecal continence } \\
\text { - } 2 \text { severe neurological impairment } \\
\text { - } 1 \text { global developmental delay } \\
\text { - } 1 \text { reduced motility of lower limbs } \\
\text { and fecal incontinence }\end{array}$ \\
\hline
\end{tabular}

consanguinity) [15]. Associated conditions included are: VACTERL association (vertebral abnormalities, anal atresia, cardiac defects, tracheal anomalies including tracheo-esophageal fistula, esophageal atresia, renal anomalies, limb anomalies, MIM:192350), amniotic band sequence, Currarino syndrome (a peculiar form of caudal regression syndrome, also known as autosomal dominant sacral agenesis, MIM:176450), Waardenburg syndrome, Joubert syndrome, Meckel-Gruber syndrome and some chromosomal abnormalities like trisomy 13, trisomy 18, triploidy and partial aneuploidy [16].

The low number of patients affected/families involved limited the diagnostic efficacy of genetic analysis. However, whole genome sequencing techniques found candidate NTDs loci and genes in chromosomes 2, 7, 10 and 17 (some of which, i.e. WIPI1, SPHKAP and NCOR1, have recently been associated with anencephaly) $[7,16]$. These insights add to our existing knowledge of the genetic mechanisms underlying NTDs development [17]. 
The ongoing genomic revolution will indeed offer the possibility to carry out genomic projects, with the aim of identifying new variants implicated in the biologic basis of NTDs [16-18].

The low rate of NTDs observed in our case series, even more marked than that currently found in HICs [8, 19-21], may be explained by some plausible factors: a likely high number of prenatal diagnoses and abortions in our setting, and the phenomenon of health emigration (from Sicily to central-northern Italian regions), that may have contributed to the reduction/underestimation of our cases.

A large number of studies provided evidence that folate fortification reduces the incidence of MMC and anencephaly (conditions known as folic acid preventable spina bifida, FAP-SB, which represent up to $92 \%$ of all NTDs) [9, 22-24]. In USA preventive policies were first implemented in 1992, with a recommendation by the Public Health Service, that all women of childbearing age should consume $400 \mu \mathrm{g}$ of folic acid daily [9]. In 1998, mandatory fortification of enriched cereal grain products was instituted, whose adoption resulted in a $28 \%$ reduction in NTDs prevalence (from 10.7 cases/1000 in 1992 to $7 / 1000$ in 1998) [9]. However, after the initial reduction, birth prevalence remained stable since 1999, with nearly a quarter (21.6\%) of childbearing age women who still have low red blood folate concentration associated with a higher risk for NTDs [9]. Furthermore, fortification mandates are still not universally adopted, and most countries (mainly LMICs) are not fortifying grains or rice with folate. Consequently, the rate of actual prevention of FAP-SB is only $13 \%[9,24]$. Therefore, also in presence of a low number of cases of NTDs, like those found in our report, prevention measures need to be improved and implemented even in HICs, also in light of the increased risks of short and long-term morbidity and disability affecting these subjects. These unfavorable outcomes are still highly prevalent also in HICs [9, 19]. Thus, despite the achievement of advanced standards of care and the improvements in neonatological management and surgical techniques $[8,25,26]$, they have been observed also in some of our patients.

Newborns and children with NTDs need a multidisciplinary approach and follow-up, involving neonatologists, neonatal surgeons, pediatric neurologists, urologists and orthopedics, geneticists, physiatrists, physiotherapists and neurorehabilitation therapists. Our multidisciplinary team aims to guarantee to children and families, an individualized care oriented to maintain normal biologic functions and social life by preserving urinary and stool continence, lowering the possible infective risk, and planning and a neurodevelopmental follow-up.

\section{Conclusions}

The awareness of the benefits of preconception folic acid supplement is still not optimum even in HICs [23]. This is consistent with the data of our report, which showed a low rate/absence of folate supplement among the mothers of our patients. Adequate medical counselling may not reach women with unplanned pregnancies, and/ or more vulnerable owing to socio-economic status. Since even in HICs, prenatal US screening cannot completely contain the impact on health systems that these defects exert in relation to the burden of complex care and morbidity/disability risks. These primary intervention remains our most important and effective tool. Thus, alternative preventive strategies should be considered. These may include fortifying commonly consumed foods and, through public health policies, allow a free availability of preconception folic acid supplements to all women of childbearing age.

Neonatologists and pediatricians should claim a leading role in national and international health as well as research policies, with the goal of preventive and curative care pertaining to disability.

Every child has the right to be protected against any disease, even more if complex and burdened by high morbidity and mortality. This is particularly true for newborns with NTDs, for whom we have an extraordinary potential of prevention available. If this is not achieved, an early, multidisciplinary, individualized and family centered as well as longitudinal management, should be guaranteed.

\section{Abbreviations}

a-CGH: Array comparative genomic hybridization; CT: Computed tomography; FAP-SB: Folic acid preventable spina bifida; HICs: High income countries; LMICs: Low and middle income countries;

MMC: Myelomeningocele; MRI: Magnetic resonance imaging; NICU: Neonatal intensive care unit; NTDs: Neural tube defects; US: Ultrasound; USA: United States of America; WG: Weeks of gestation

\section{Acknowledgements}

Not applicable.

\section{Authors' contributions}

EP performed neonatal neurological assessment and developmental followup, revised the manuscript, and gave final approval of the version to be submitted. GS collected clinical data, analyzed the database and drafted the manuscript. IAM S contributed to the clinical management of the patients. MG contributed to the clinical management of the patients. GC conceptualized the study, revised the manuscript and gave final approval of the version to be submitted. The authors read and approved the final manuscript.

\section{Funding}

No funding was granted for this research.

\section{Ethics approval and consent to participate}

Written informed consent was obtained from both parents at birth or admission of their newborns. The study was approved by the Mother and Child Department of the University of Palermo (Palermo, Italy). All procedures performed in this study were in accordance with the ethical standards of the institutional and national research committee, and with the 1964 Helsinki declaration and its later amendments or comparable ethical standards. 


\section{Consent for publication}

Not applicable.

\section{Competing interests}

The authors declare that they have no competing interests.

Received: 24 April 2020 Accepted: 19 May 2020

Published online: 24 May 2020

\section{References}

1. Piro E, Alongi A, Domianello D, Sanfilippo C, Serra G, Pipitone L, Ballacchino A, Provenzano C, Schierz IAM, Corsello G. Malformations of central nervous system: general issues. Acta Medica Mediterranea. 2013;29:735-40..

2. Wallingford JB, Niswander LA, Shaw GM, Finnell RH. The continuing challenge of understanding, preventing, and treating neural tube defects. Science. 2013;339(6123):1222002.

3. Serra G, Antona V, Schierz M, Vecchio D, Piro E, Corsello G. Esophageal atresia and Beckwith-Wiedemann syndrome in one of the naturally conceived discordant newborn twins: first report. Clin Case Rep. 2018;6:399-401.

4. Greene ND, Copp AJ. Neural tube defects. Annu Rev Neurosci. 2014;37:221-42.

5. Lew SM, Kothbauer KF. Tethered cord syndrome: an updated review. Pediatr Neurosurg. 2007:43(3):236-48.

6. Rolo A, Galea GL, Savery D, Greene NDE, Copp AJ. Novel mouse model of encephalocele: post-neurulation origin and relationship to open neural tube defects. Dis Model Mech. 2019:12:dmm040683.

7. Wang L, Ren A, Tian T, Li N, Cao X, Zhang P, Jin L, Li Z, Shen Y, Zhang B, Finnell RH, Lei $Y$. Whole-exome sequencing identifies damaging de novo variants in anencephalic cases. Front Neurosci. 2019;13:1285.

8. Gandy K, Castillo H, Rocque BG, Bradko V, Whitehead W, Castillo J. Neurosurgical training and global health education: systematic review of challenges and benefits of in-country programs in the care of neural tube defects. Neurosurg Focus. 2020;48:E14.

9. Estevez-Ordonez D, Davis MC, Hopson B, Arynchyna A, Rocque BG, Fieggen G, Rosseau G, Oakley G, Blount JP. Reducing inequities in preventable neural tube defects: the critical and underutilized role of neurosurgical advocacy for folate fortification. Neurosurg Focus. 2018:45:E20.

10. Kabré A, Zabsorne DS, Sanou A, Bako Y. The cephaloceles: a clinical, epidemiological and therapeutic study of 50 cases. Neurochirurgie. 2015;61:250-4.

11. Serra G, Miceli V, Albano S, Corsello G. Perinatal and newborn care in a two years retrospective study in a first level peripheral hospital in Sicily (Italy). Ital J Pediatr. 2019:45:152.

12. Forestus P: De capitis et cerebre morbis ac symptomatic, in: Observationum et curationum medicinalium, libri III. Leiden: Officina Platiniana, 1587.

13. Piro E, Schierz IAM, Giuffrè M, Cuffaro G, La Placa S, Antona V, Matina F, Puccio G, Cimador M, Corsello G. Etiological heterogeneity and clinical variability in newborns with esophageal atresia. Ital J Pediatr. 2018:44(1):19.

14. Castillo J, Gandy K, Bradko V, Castillo H. Language and Latino immigrants living with spina bifida: social determinants of health - the missing dimension in quality of life research. J Pediatr Rehabil Med. 2019;12:345-59.

15. Hamamy H. Epidemiological profile of neural tube defects in Arab countries. Middle East J Med Genet. 2014:3:1-10.

16. Salih MA, Murshid WR, Seidahmed MZ. Classification, clinical features, and genetics of neural tube defects. Saudi Med J. 2014;35(Suppl 1):S5-S14.

17. Lemay $P$, De Marco P, Traverso M, Merello E, Dionne-Laporte A, Spiegelman D, Henrion É, Diallo O, Audibert F, Michaud JL, Cama A, Rouleau GA, Kibar Z, Capra V. Whole exome sequencing identifies novel predisposing genes in neural tube defects. Mol Genet Genomic Med. 2019;7:e00467.

18. Chen $Z$, Lei $Y$, Zheng $Y$, Aguiar-Pulido $V$, Ross ME, Peng R, Jin L, Zhang $T$, Finnell $\mathrm{RH}$, Wang $\mathrm{H}$. Threshold for neural tube defect risk by accumulated singleton loss-of-function variants. Cell Res. 2019;29:776.

19. Gregersen NH, Kvist K, Hindsø K, Born AP, Hoei-Hansen CE. The clinical features of paediatric neural tube defects changed in a tertiary care Centre between 1997 and 2015. Acta Paediatr. 2017:106:837-40.

20. Blencowe H, Kancherla V, Moorthie S, Darlison MW, Modell B. Estimates of global and regional prevalence of neural tube defects for 2015: a systematic analysis. Ann N Y Acad Sci. 2018;1414:31-46.

21. Zaganjor I, Sekkarie A, Tsang BL, Williams J, Razzaghi H, Mulinare J, Sniezek $\mathrm{JE}$, Cannon MJ, Rosenthal J. Describing the prevalence of neural tube defects worldwide: a systematic literature review. PLoS One. 2016;11: e0151586.
22. Williams J, Mai CT, Mulinare J, Isenburg J, Flood TJ, Ethen M, Frohnert B, Kirby RS. Centers for Disease Control and Prevention. Updated estimates of neural tube defects prevented by mandatory folic Acid fortification - United States, 1995-2011. MMWR Morb Mortal Wkly Rep. 2015;64:1-5.

23. De-Regil LM, Peña-Rosas JP, Fernández-Gaxiola AC, Rayco-Solon P. Effects and safety of periconceptional oral folate supplementation for preventing birth defects. Cochrane Database Syst Rev. 2015;12:CD007950.

24. Arth A, Kancherla V, Pachón H, Zimmerman S, Johnson Q, Oakley GP Jr. A 2015 global update on folic acid-preventable spina bifida and anencephaly. Birth Defects Res A Clin Mol Teratol. 2016;106:520-9.

25. Horzelska El, Zamlynski M, Horzelski T, Zamlynski J, Pastuszka A, Bablok R, Herman-Sucharska I, Koszutski T, Olejek A. Open fetal surgery for myelomeningocele - is there the learning curve at reduction mother and fetal morbidity? Ginekol Pol. 2020;91(3):123-31.

26. Bradko V, Castillo H, Janardhan S, Dahl B, Gandy K, Castillo J. Towards guideline-based Management of Tethered Cord Syndrome in Spina bifida: a Global Health paradigm shift in the era of prenatal surgery. Neurospine. 2019;16:715-27.

\section{Publisher's Note}

Springer Nature remains neutral with regard to jurisdictional claims in published maps and institutional affiliations.

\section{Ready to submit your research? Choose BMC and benefit from:}

- fast, convenient online submission

- thorough peer review by experienced researchers in your field

- rapid publication on acceptance

- support for research data, including large and complex data types

- gold Open Access which fosters wider collaboration and increased citations

- maximum visibility for your research: over $100 \mathrm{M}$ website views per year

At BMC, research is always in progress.

Learn more biomedcentral.com/submissions 